\title{
PRÁTICAS, DISCURSOS E ARENAS: NOTAS SOBRE A SOCIOANTROPOLOGIA DO DESENVOLVIMENTO
}

A combinação de heranças da etnologia e da sociologia da escola de Chicago caracteriza uma das mais profícuas e atuais abordagens teóricas para o estudo dos processos de desenvolvimento. Trata-se da socioantropologia do desenvolvimento, ${ }^{1}$ que se contrapõe à sociologia quantitativista, à etnologia patrimonialista focalizada no informante privilegiado e às sociologia e antropologia ensaísticas, privilegiando o estudo empírico multidimensional dos grupos sociais, através da análise de suas práticas e representações (ver Olivier de Sardan, 1995, 2008; Bierschenck, 2007).

Este artigo pretende discutir a contribuição e os limites desse tipo de análise ${ }^{2}$ a partir da abordagem elaborada por Olivier de Sardan e seus colegas da Associação Euro-Africana para a Antropologia da Mudança Social e o Desenvolvimento (APAD), ${ }^{3}$ que propõe uma ferramenta de investigação não-normativa sobre os processos de desenvolvimento e apresenta diversas inovações metodológicas para o estudo desses processos, combinando rigor analítico com um diálogo respeitoso com os grupos que são objeto da intervenção dos dispositivos de desenvolvimento.

O texto vai articular dois níveis de reflexão. Em um primeiro momento, a ênfase se dará sobre a trajetória recente dos estudos sobre processos de desenvolvimento, que, partindo de uma crítica à sociologia do desenvolvimento e à antropologia para o desenvolvimento, enunciam o surgimento de novas abordagens. Nesse momento daremos ênfase ao surgimento da crítica à antropologia do desenvolvimento realizada por autores pós-estruturalistas (Escobar, 1991; Viola, 2000) e ao surgimento da socioantropologia do desenvolvimento (Olivier de Sardan, 1995, 2001; Bierschenck, 2008).

Em um segundo momento, o foco será direcionado para a discussão da socioantropologia do desenvolvimento, destacando a metodologia dessa proposta de investigação. Os pontos fortes e fracos dessa abordagem serão objeto de análise, com destaque para as virtudes associadas a uma proposta de investigação centrada na pesquisa qualitativa, e para os problemas relacionados a certo ecletismo teórico e à utilização de conceitos oriundos de tradições intelectuais diferentes. 
Neste segundo momento apresento os principais elementos que os autores da socioantropologia do desenvolvimento destacam como constitutivos de sua abordagem, procurando, ao mesmo tempo, estabelecer uma separação com crítica discursiva do desenvolvimento ${ }^{4}$ (Escobar, 1991) e uma identificação com a sociologia do desenvolvimento centrada nos atores de Norman Long e seus colegas da Universidade de Wageningen ${ }^{5}$ (Long, 1994; 2007; Arce \& Long, 2007).

Ao longo desta segunda parte destaco também as principais críticas levantadas por autores da escola de Wageningen (Arce \& Long, 2007) à tentativa de Olivier de Sardan e seus colegas de fundar uma socioantropologia do desenvolvimento baseada no conceito do entrelaçamento das lógicas sociais (Olivier de Sardan, 2001; Bierschenck, 2007) e sustento a necessidade de diferenciar a utilização dos conceitos de campo e arena para dar conta das relações de poder presentes nas situações analisadas pela socioantropologia do desenvolvimento.

\section{A SOCIOANTROPOLOGIA E AS NOVAS ANTROPOLOGIAS DO DESENVOLVIMENTO}

A trajetória dos estudos sobre o desenvolvimento pode ser associada, pelo menos nas duas décadas posteriores à Segunda Guerra Mundial, aos destinos da sociologia e da economia do desenvolvimento. Como sublinhou Raymond Boudon, num artigo que examina as causas do declínio desse tipo de abordagem:

[...] quando fazemos a lista de trabalhos sociológicos, de ciência política ou de economia que chamaram a atenção, ou dos grandes nomes associados à noção de desenvolvimento, podemos assinalar sem dificuldade que esses trabalhos datam, em sua maioria, dos anos cinquenta e sessenta, com seu declínio iniciando nos anos setenta (Boudon, 2000, p. 253).

Esse período de apogeu da sociologia e da economia do desenvolvimento foi também a idade de ouro das explicações macrossociológicas sobre os fatores do atraso, do tradicionalismo, do subdesenvolvimento e dos mecanismos (teorias) necessários para superá-los. Para Long (1994, 2007), o predomínio desse tipo de abordagem estrutural, somado às fragilidades das análises dos processos de desenvolvimento que tomavam a perspectiva do ator como um elemento central, acabou por contribuir para o declínio dos estudos sobre o desenvolvimento.

No caso específico dos Estados Unidos, a trajetória de inserção de profissionais da antropologia nas instituições responsáveis pelo assessoramento das ações de desenvolvimento percorreu, ao longo do século XX, pelo menos três fases importantes. ${ }^{6}$ De acordo com Ranc (1988), um primeiro momento de força ocorreu no período posterior à Segunda Guerra Mundial, trabalhando em organismos internos (Bureau of Indian Affairs) e na divisão de desenvolvimento comunitário da ICA (International Cooperation Administration), passando por 
um período de crise no final dos anos 1960, quando eclodiram denúncias da participação de antropólogos em ações de contra-insurgência nos países do chamado Terceiro Mundo, tendo um renascimento nos anos 1970, com o processo de reorganização da agência americana de desenvolvimento internacional (USAID), sucessora da ICA. ${ }^{7}$

Ainda segundo essa autora, a abordagem antropológica elaborada nesse último período, com a ocupação de postos na USAID e em outras agências de desenvolvimento, será caracterizada por sua "modernidade, novidade, construtiva, desembaraçada de seus complexos", adotando uma "abordagem positiva e corajosa do chamado desenvolvimento, mesmo quando considerado os aspectos negativos provocados pelo progresso técnico". Segundo essa ótica, o desenvolvimento econômico e social é um bem cujos efeitos positivos devem ser divididos com as populações mais desprovidas e que os profissionais da antropologia do desenvolvimento deveriam ser capazes, "quando colocados frente a um tipo específico de projeto, de prever, com uma precisão considerável, de que maneira as populações locais vão responder" (Ranc, 1988: 458-463).

Um dos autores centrais no estabelecimento dessa antropologia do desenvolvimento será Michael Cernea, então conselheiro do Banco Mundial, que organizará a obra Primeiro as pessoas: variáveis sociológicas no desenvolvimento rural (Cernea, 1995), sintetizando a experiência dessa antropologia do desenvolvimento inserida nas instituições internacionais de cooperação. Como descreve esse autor, na segunda metade dos anos 1970 houve uma incorporação mais forte dos conhecimentos socioantropológicos nas ações de desenvolvimento.

A mudança, que consistiu em deslocar a ênfase quase exclusiva da infraestrutura física para o reconhecimento das estruturas sociais e em reorientar um oscilante etnocentrismo presente nas intervenções de desenvolvimento para o reconhecimento das culturas indígenas, fez parte de uma viragem para projetos de desenvolvimento centrados nos protagonistas (as pessoas) (Cernea, 1995: 26).

O trabalho desses antropólogos inseridos nas instituições de desenvolvimento será classificado por Escobar (1997) como de uma antropologia para o desenvolvimento (development anthropology). Segundo Escobar, a antropologia associada ao desenvolvimento surgiu em função dos insucessos da teoria e da prática do desenvolvimento ${ }^{8}$ e concretizou-se com a entrada de antropólogos no corpo de funcionários das agências internacionais de desenvolvimento (USAID, Banco Mundial) e da incorporação dos fatores sociais e culturais nas análises sobre o desenvolvimento (Escobar, 1991: 666).

Como sublinhou Hart (2002: 8), essa entrada em cena dos antropólogos no corpo funcional das agências de desenvolvimento implicou a realização de estudos próprios à abordagem dessa disciplina, “com seus métodos de pesquisa de campo, a imersão por um longo período de tempo junto ao grupo estudado, a ideologia de ir ao encontro das pessoas [...], uma hostilidade geral face aos métodos estatísticos, aos documentos literários e todas as técnicas da buro- 
cracia", cujos trabalhos mais importantes serão produzidos por autores como Cernea e Horowitz.

Nos anos 1990, outra vertente da antropologia norte-americana se interessará pelo estudo dos processos e práticas do desenvolvimento (Viola, 2000; Faugère, 2000), assumindo o rótulo de antropologia do desenvolvimento e contrapondo-se frontalmente à antropologia para o desenvolvimento (Escobar, 1997).

Rompendo de forma decidida com a própria noção de desenvolvimento, essa corrente questionará os pressupostos impensados da utilização dessa noção, acentuando as relações de poder subjacentes à prática desenvolvimentista e ao papel performativo do seu discurso.

A antropologia do desenvolvimento começa colocando em questão a noção mesma de desenvolvimento, fazendo valer, segundo uma perspectiva pós-estruturalista, que se nós desejamos compreender o desenvolvimento, devemos examinar como ele foi compreendido historicamente, segundo quais perspectivas, quais princípios de autoridade e com que tipo de consequências para determinados grupos de pessoas (Escobar, 1997: 546).

Essa análise pós-estruturalista do desenvolvimento desloca seu foco da relação entre agentes do desenvolvimento e a população objeto de suas ações, tematizando a gênese e o estabelecimento da noção de desenvolvimento (como domínio do discurso e da ação), colocando em relevo três elementos: a) as formas de conhecimento subjacentes ao discurso do desenvolvimento; b) os sistemas de poder que regulam a prática do desenvolvimento; e, c) as formas de subjetividade mantidas por esse discurso e que estruturam a diferença desenvolvidos/subdesenvolvidos (Escobar, 1996: 31; Lebrecque, 2000: 15).

Para essa abordagem, o sistema de ajuda ao desenvolvimento é visto como uma máquina que despolitiza os temas que deve enfrentar (redução da pobreza, combate ao desmatamento, redução do aquecimento global etc.), que inventa problemas com os quais sua expertise pode lidar e que desconsidera outros que seriam politicamente espinhosos (Escobar, 1991: 667; Faugère, 2000: 11).

Em entrevista na qual realiza um balanço da sua abordagem, Arturo Escobar destaca um conceito como central - o de regularidade discursiva (Foucault) - para os estudos inspirados na antropologia do desenvolvimento. Este conceito ele utilizará para criticar o que seria a principal marca do campo de atuação das agências e dos profissionais do desenvolvimento, como aparece nesse excerto de entrevista concedida por ele a Andreu V. Recasens.

Creio que as críticas feitas a esse trabalho sobre desenvolvimento (tanto o meu como os de outras pessoas em uma linha muito próxima, porém, centrando-me neste caso em meu livro) em geral são muito pertinentes. [...] Contudo, penso que o argumento geral, nos marcos do que faz a análise do discurso, o que Foucault chama de as regularidades discursivas, em termos da posição do sujeito desde a qual se pode falar sobre o desenvolvimento, creio que o argumento continua sendo válido, no sentido de que para falar de desenvolvimento - seja uma pequena ONG 
ou o Banco Mundial - essa posição tem que estar no mesmo espaço discursivo. [...] Ou seja, se alguém iria falar de desenvolvimento - pelo menos até o final dos anos 1980 - teria que repetir o discurso, e assim foi, com muitas variações, porque o discurso do Banco Mundial sem dúvida é muito distinto do discurso de muitas ONGs, porém, num dado nível, no plano das regularidades discursivas, me parece que todos os agentes que ocuparam ou que continuam ocupando esse grande espaço discursivo do desenvolvimento teriam que se envolver com esse discurso (Recasens, 2000: 149).

Essa ruptura com o discurso do desenvolvimento levará Escobar (1997: 554) a propugnar uma nova forma de pensar a relação com a ideia de que as sociedades devem ser modificadas por algo definido como o desenvolvimento, dando origem ao termo vagamente definido de pós-desenvolvimento, ${ }^{9}$ termo com o qual pretende reunir experiências realizadas por grupos sociais autônomos, a partir de situações locais isoladas da lógica do capital e da ação estatal.

De forma semelhante, num artigo em que critica o conceito de desenvolvimento sustentável, ele propõe uma nova linguagem para tratar das relações entre sociedade e natureza que permita "às comunidades e nações do terceiro mundo reposicionarem-se nos espaços das conversações e processos globais que estão (re)configurando o mundo" (Escobar, 1995: 21).

Outra vertente de renovação da antropologia do desenvolvimento será estabelecida por pesquisadores europeus no âmbito da Associação Euro-Africana pela Antropologia da Mudança Social e do Desenvolvimento (APAD). Segundo Bierschenk (2008), essa antropologia do desenvolvimento tipicamente europeia tem suas raízes nos trabalhos de Norman Long, na Universidade de Wageningen, e de J-P. Olivier de Sardan, na Escola de Altos Estudos em Ciências Sociais (EHESS) de Marselha.

Para Olivier de Sardan (2001) o ponto comum dessas duas tradições que confluíram para a antropologia do desenvolvimento da APAD é a atenção conferida à dinâmica das lógicas sociais presentes nas situações de interação em que desenrolam as ações de desenvolvimento.

Essa perspectiva da diversidade de lógicas sociais em imbricação e em interação foi desenvolvida, no que concerne à antropologia do desenvolvimento, por dois polos, de maneira independente: um polo principalmente anglófono, em torno de Norman Long, na Holanda; um polo mais francófono, configurado pela APAD (Olivier de Sardan, 2001: 743).

Apesar da crítica às práticas e aos discursos das agências de desenvolvimento, os trabalhos desses pesquisadores tomam certa distância da abordagem pós-estruturalista do desenvolvimento, ${ }^{10}$ estabelecendo como programa de investigação o exame aprofundado dos processos de mudança socioeconômica e política, procurando tornar exótico o conceito de desenvolvimento, analisando-o como uma situação específica. Para esses autores o desenvolvimento pode ser concebido como: 
o conjunto dos processos sociais induzidos por operações voluntaristas de transformação de um meio social, empreendidos por meio de orientação de instituições ou atores exteriores a esse meio, e que se baseiam no transplante de recursos e/ou técnicas e/ou saberes. Essa definição pode se aplicar às ações de desenvolvimento operacionalizadas tanto nos países do Norte como aqueles do Sul. É a presença de uma configuração desenvolvimentista que define a existência mesma do desenvolvimento, isto é, esse universo largamente cosmopolita de experts, de administradores, de responsáveis por ONGs, de pesquisadores, de técnicos, de chefes de projetos, de agentes de campo, de intermediários, de animadores de grupos ou de associações, que vivem de alguma forma do desenvolvimento dos outros e mobilizam ou gerem, por conta disso, recursos materiais e simbólicos consideráveis (Olivier de Sardan, 1995: 7).

Outro aspecto que pode ser considerado como um ponto forte da antropologia do desenvolvimento da APAD é a importância conferida aos atores nos processos de desenvolvimento. De forma semelhante à antropologia desenvolvida pelos pesquisadores da Universidade de Wageningen (Long, 1994), os estudos da APAD observam os atores como capazes e competentes, tomando para análise as interações que ocorrem ao longo das ações de desenvolvimento.

A importância metodológica conferida aos atores (suas estratégias e suas lógicas) leva Olivier de Sardan e colegas a privilegiarem a análise dos atores em interação em arenas específicas, tomando a dimensão do conflito como uma porta de entrada para seus estudos (Bierschenck, 2007). Nesse tipo de abordagem a interação ${ }^{11}$ dos atores da situação de desenvolvimento é tratada como uma "entrada fecunda na realidade social, meio para decifrar as estratégias dos atores e os constrangimentos dos contextos", permitindo o acesso às práticas e às representações, aos fenômenos conjunturais e estruturais (Olivier de Sardan, 2001: 742).

Um conceito central dessa abordagem é o do entrelaçamento (enchevêtrement) das lógicas sociais, que compreende a situação de desenvolvimento como "um campo social que coloca em relação, com uma intensidade particular, atores diversos, interesses heterogêneos, lógicas de ação plurais e universos simbólicos divergentes" (Bierschenck, 2007). Este cruzamento produz realidades múltiplas e divergentes, uma interação que tem como resultado final uma situação social diferente da projetada pelos atores, com características próprias, que não estão presentes no momento inicial do processo.

Podemos dizer que essa orientação da socioantropologia do desenvolvimento, de considerar os atores que são objetos da ação de desenvolvimento como capazes, como coprodutores das intervenções de desenvolvimento, se insere em um movimento mais geral da socioantropologia francesa contemporânea ${ }^{12}$ que, contrapondo-se às abordagens estruturalistas, destaca as competências e a capacidade dos atores em interferir nos seus respectivos contextos de atuação (Boltanski, 1990; Dosse, 1995; Olivier de Sardan, 2008b). Ou seja, trata-se de um tipo de abordagem que, mesmo considerando os contextos e os 
constrangimentos que envolvem qualquer ação, destaca os atores como capazes de interferir nas ações e nas políticas que lhes são direcionadas.

Entretanto, no processo de valorização do ator, essa socioantropologia do desenvolvimento faz questão de se dissociar da abordagem que classifica como "populismo ideológico", cujo principal defeito consiste na valorização de forma acrítica da capacidade de ação dos grupos sociais marginalizados, identificando nas populações rurais ou no campesinato somente qualidades positivas (Olivier de Sardan, 1995: 105). Contra esse tipo de populismo ${ }^{13}$ a socioantropologia do desenvolvimento vai defender o populismo metodológico, que "considera que os grupos ou atores de baixo possuem conhecimentos e estratégias que precisam ser investigadas, mas, sem se pronunciar sobre seu valor ou sua validade" (Olivier de Sardan, 2001: 738).

Essa nova forma de analisar implica tomar os processos de desenvolvimento em seus diversos níveis, articulando diferentes escalas de análise, "desde os grupos focais dos projetos, a burocracia desses projetos, as categorias que orientam as práticas dos agentes do desenvolvimento, os aparatos do Estado e seu pessoal, as organizações do desenvolvimento (governamentais ou não), burocracias nacionais e multilaterais do desenvolvimento" (Bierschenck, 2007).

Como indica essa breve revisão de literatura, a reflexão antropológica sobre a prática e o discurso das ações de desenvolvimento ganhou impulso nas últimas décadas do século XX, permitindo, por um lado, a forte crítica das ações de desenvolvimento e, por outro, a constituição de uma disputa teórica entre (pelo menos) duas formas de apresentar o que seria uma renovada antropologia do desenvolvimento. Este debate pode ser apresentado como o confronto entre a corrente centrada na desconstrução do discurso do desenvolvimento e a versão crítica da ação desenvolvimentista centrada na abordagem do entrelaçamento das lógicas sociais (APAD). ${ }^{14}$

Entretanto, apesar dessas divergências, vale destacar a existência de pontos comuns reclamados por essas duas abordagens. Dois deles nos parecem mais estimulantes, caso da abertura de novos campos de investigação ${ }^{15}$ e da necessidade de renovação dos estudos sobre o desenvolvimento pelo conjunto das ciências sociais, uma vez que ela exige a construção de novos conceitos, a elaboração de novas estratégias de investigação e de novos dispositivos metodológicos, questões que exploraremos na próxima seção deste artigo. 


\section{SOBRE OS MÉRITOS DA SOCIOANTROPOLOGIA DO DESENVOLVIMENTO}

A abordagem da socioantropologia do desenvolvimento possui diversos méritos, dentre os quais considero como os mais importantes a sua ênfase na produção de estudos sobre processos de desenvolvimento com forte ancoragem empírica e a procura de uma abordagem teórica consistente, recusando o discurso fácil do desconstrutivismo e do chamado populismo ideológico.

A preocupação com a dimensão teórica está relacionada com a necessidade de dissociar a antropologia do desenvolvimento de uma simples aplicação de conhecimentos antropológicos, procurando conferir legitimidade a essa subdisciplina, de forma que ela possa ser considerada como um campo de estudos tão nobre quanto os objetos mais clássicos da antropologia (parentesco e religião) (Olivier de Sardan, 2004; Bierschenck, 2008).

Outra característica importante da socioantropologia do desenvolvimento é a recusa da separação ${ }^{16}$ (grand partage) de objetos de estudo entre a sociologia e a antropologia. Nesse sentido, ela procura combinar as tradições da sociologia da Escola de Chicago com a pesquisa etnográfica (Olivier de Sardan, 1995: 10). Vale dizer que essa aproximação de objetos de estudo e de métodos de investigação deu origem a um conjunto importante de trabalhos nas ciências sociais francesas que reivindica, de forma explícita ou implícita, a etiqueta de socioantropologia, cuja singularidade seria, segundo Juan (2005), o desenvolvimento de uma técnica de pesquisa específica, unindo entrevista e observação de campo.

A reivindicação da herança metodológica da etnologia (não culturalista) e da sociologia da Escola de Chicago leva a socioantropologia do desenvolvimento a destacar a necessidade do "rigor do qualitativo", colocando a pesquisa de campo em suas diferentes perspectivas como o método de investigação por excelência (Olivier de Sardan, 2008a), ao mesmo tempo em que propugna a recusa de uma posição normativa e a utilização reflexiva das principais aquisições dos métodos de pesquisa centrados no trabalho de campo.

Com efeito, em um domínio - o desenvolvimento - saturado de pontos de vista morais e normativos [...] - essa antropologia do desenvolvimento, [...], dá primazia à enquete, recusa tanto quanto possível os a priori morais e ideológicos e utiliza vários métodos da pesquisa de campo habituais da etnologia, para estudar, simultaneamente, as instituições do desenvolvimento e as populações que com elas se relacionam, as interações entre "développeurs et développés" e as estratégias de atores pertencentes a mundos sociais diferentes que são colocados em contato pela prática e pelas políticas do desenvolvimento (Olivier de Sardan, 2007: 547).

O estado de alerta quanto à intromissão de aspectos morais e normativos nas análises da socioantropologia do desenvolvimento não implica uma postura naïf ou positivista quanto à relação entre interesses sociais e ciência, 
mas uma preocupação em definir procedimentos de investigação que permitam o controle desses aspectos, de forma que as influências relativas às escolhas políticas do pesquisador situem-se a montante e a jusante do processo de investigação (Olivier de Sardan, 2008a: 328).

Nesse mesmo sentido podemos identificar a análise apresentada por Lavigne-Delville (1999), cujo foco é a relação entre a produção de conhecimentos pelas ciências sociais e apreciação de problemas colocados pelos atores no campo do desenvolvimento. Para esse autor, a socioantropologia do desenvolvimento não desconhece a necessidade da crítica às instituições e aos procedimentos das agências de desenvolvimento, bem como das relações de poder presentes nas diversas arenas das ações de desenvolvimento, contudo, procura também oferecer: ${ }^{17}$

[...] ferramentas de análise e de distanciamento crítico para aqueles que no interior desse sistema procuram realizar honestamente seu trabalho e a favorecer a construção de dispositivos de intervenção cujas montagens institucionais, métodos de trabalho e procedimentos de decisão se apoiem sobre o reconhecimento e que levem em consideração os jogos entre os atores e que permitam um certo reequilíbrio das relações de poder (autonomia de decisão, acesso a informação, acesso aos financiamentos etc.) entre os atores, tornando a intervenção menos heterônoma (Lavigne-Delville, 1999: 26).

No plano mais específico da operacionalização dessa abordagem sobre estudos de desenvolvimento gostaria de destacar duas contribuições: i) a análise dos diferentes níveis de coerência da ação desenvolvimentista e, ii) a discussão sobre o papel desempenhado pelas representações e estereótipos incorporados pelos atores da configuração desenvolvimentista.

\subsection{Sobre a coerência dos projetos de desenvolvimento e sua recepção pelo chamado público-alvo}

Um dos pontos mais destacados pelas análises da socioantropologia do desenvolvimento diz respeito aos desencontros entre os objetivos visados e os resultados obtidos pela ação de desenvolvimento. ${ }^{18}$ Enquanto numa abordagem pós-estruturalista esse gap seria visto como um dado quase que imanente da ação desenvolvimentista, a socioantropologia do desenvolvimento destaca dois aspectos que dificultam a coincidência entre objetivos e resultados: i) a complexidade que marca a execução de um projeto de desenvolvimento e os diferentes níveis de coerência que devem ser alcançado nessa execução; e, ii) o tipo de recepção/reação que esse projeto terá de seu público-alvo.

No caso da primeira questão, Olivier de Sardan (1995) sugere a existência de pelo menos quatro níveis de coerência que um projeto de desenvolvimento deve apresentar. O primeiro nível corresponde à coerência do projeto com o paradigma que lhe orienta. O segundo está relacionado com a adequação do projeto ao ambiente macroeconômico em que se encontra inserido. A terceira dimensão refere-se à coerência entre os objetivos apresentados pelo projeto e a 
atuação prática dos organismos financiadores, enquanto o quarto e último nível de coerência está relacionado com a lógica de funcionamento da organização que realiza o projeto.

A observação desses diferentes níveis de coerência que devem perpassar uma ação de desenvolvimento aponta para a complexidade inscrita na operacionalização de um projeto, cuja execução "envolve um conjunto diferenciado de atores sociais, oriundos de mundos diferentes e cujos comportamentos são orientados por lógicas múltiplas" (Olivier de Sardan, 1995: 125).

Para exemplificar a pertinência dessas orientações indicadas pela socioantropologia do desenvolvimento apresento a seguir alguns exemplos de contradições entre os níveis de coerência de ações (projetos) de desenvolvimento que estudei nos últimos anos.

O primeiro caso refere-se à proposta de desenvolvimento regional integrado apresentada pelo governo federal quando da execução do Programa Grande Carajás, na Amazônia Oriental brasileira (Pinto, 1982), cujos resultados mostraram que a ideia de desenvolvimento regional integrado, articulando as diferentes regiões e setores econômicos da região atravessada pela principal infraestrutura do Programa (a Estrada de Ferro Carajás), ficaram apenas no papel.

Tomando o argumento da necessária coerência entre os diferentes níveis de coerência de um projeto desenvolvimento, podemos nos perguntar se a conjuntura econômica na qual esse Programa foi elaborado não continha de antemão os fundamentos de seu fracasso enquanto ação de desenvolvimento regional integrado, uma vez que sua apresentação ocorreu num momento em que o Estado brasileiro passava a enfrentar dificuldades de financiamento e com a redução de sua capacidade operacional na região Amazônica (Carneiro, 1994).

Da mesma forma, poderíamos indagar o que poderia ser esperado das ações de apoio a pequenos projetos de desenvolvimento sustentável dirigidos por organizações indígenas e camponesas na Amazônia brasileira pelo Programa Piloto de Proteção às Florestas Tropicais (PPG-7), ${ }^{19}$ quando todo um conjunto de políticas (fundiária, agrícola, creditícia, fiscal etc.) operava em sentido contrário ao desenvolvimento da produção agroextrativista?

Outro aspecto destacado pela socioantropologia do desenvolvimento refere-se às diferentes formas pelas quais um projeto de desenvolvimento é recebido por seu público-alvo. Segundo essa abordagem, dois princípios operam nessas situações: um princípio de seleção e um princípio de contorno do projeto (Olivier de Sardan, 1995). Tanto em um caso como em outro o que prevalece é a ideia que o público da ação desenvolvimentista não é passivo, atuando, pelo contrário, através de mecanismos de seleção e de recusa do que lhe é proposto pelo dispositivo da ação de desenvolvimento. 
Esses princípios são operados de forma diferenciada segundo o contexto e as lógicas que presidem a ação do público-alvo, que, segundo Olivier de Sardan (1995: 134-137) pode funcionar numa perspectiva de obter segurança, de ampliar o tempo ou o escopo dos benefícios recebidos, ou simplesmente de se apropriar do que lhe é oferecido pela ação de desenvolvimento.

Um exemplo dessas estratégias (de seleção e de contorno) operando num projeto de desenvolvimento pode ser vista no caso da proposta de inclusão de assentados de reforma agrária no abastecimento de matéria-prima para a indústria madeireira na Amazônia, denominada de florestas familiares (Lima et al., 2003). Elaborada com o intuito de viabilizar a exploração da reserva legal dos assentamentos e de favorecer economicamente os assentados, a proposta acabou sendo instrumentalizada por agentes da indústria madeireira, que viram nela a possibilidade de obter o recurso florestal necessário, sem se comprometer com as exigências de logo prazo que a exploração através do manejo florestal exige (Carneiro, 2012).

\subsection{Representações e estereótipos do mundo a ser "ajudado"}

Um último aspecto que pode ser destacado dessa abordagem é a constatação de que a ação desenvolvimentista é organizada a partir de "um conjunto de representações que estruturam a percepção que os atores da configuração desenvolvimentista possuem do mundo desejado e do mundo real" (Olivier de Sardan, 1995: 59). Essas representações do senso comum douto, chamadas pelo autor de infraideologias do desenvolvimento, que são partilhadas pelos atores presentes na configuração desenvolvimentista, qualquer que seja sua filiação política, são normalmente produzidas a partir de teorizações acadêmicas e possuem como principal defeito o fato de procurar generalizar explicações que são necessariamente parciais.

Outra forma de apresentar esse descompasso entre realidade (real de referência) e a interpretação científica ${ }^{20}$ aparece para os autores da socioantropologia do desenvolvimento como o produto das diferentes formas que levam ao que eles denominam dos equívocos da superinterpretação, isto é, relacionado com a projeção de um excesso de sentido sobre a análise dos dados (Olivier de Sardan, 2008a: 259). Esse excesso interpretativo é visto como o resultado de duas tendências, como o fruto de "uma projeção excessiva de preconcepções e/ou de uma preguiça metodológica", cujo resultado se manifesta de formas diversas (redução da explicação a um único fator, obsessão da coerência, generalização abusiva etc.), quando da elaboração de interpretações sobre a realidade estudada.

Essa preponderância do estereótipo sobre a realidade é um aspecto comumente observável em ações (políticas públicas) que têm o campesinato como público-alvo. No caso brasileiro ele aparece geralmente com a identificação dos camponeses como um grupo social avesso aos estímulos 
de mercado ou incapazes de adotar os padrões ditos modernos da tecnologia agrícola.

Por outro lado, podemos destacar que essa substituição da realidade pelo estereótipo não é privilégio somente das agências internacionais de desenvolvimento ou de projetos oriundos de órgãos governamentais, mas que perpassam o conjunto do campo das ações de desenvolvimento, influenciando as ações de entidades e ONGs situadas no polo dominado desse campo, como pode ser visto na tendência a considerar os camponeses (ou as mulheres camponesas) como propensos a uma relação mais sustentável (ou agroecológica ${ }^{21}$ ) com o meio ambiente, desconsiderando o contexto dessa relação ou a trajetória do grupo estudado.

Esses exemplos mostram a inadequação da tentativa de indexação de uma substância ao comportamento dos atores sociais que são o alvo da atuação desenvolvimentista (ou pós-desenvolvimentista, nos termos de Escobar), pois, como aponta a teorização sociológica contemporânea, na observação e descrição do mundo social é preciso escapar das tentações essencialistas de definição dos atores (agentes) sociais, procurando pensá-los sempre segundo sua trajetória histórica, o contexto de inserção e a relação estabelecida com outros atores (agentes) (Bourdieu \& Wacquant, 1992).

\section{LIMITES DA ABORDAGEM}

Umas das características mais salientes da socioantropologia do desenvolvimento é a tranquilidade com que seus autores circulam entre as diferentes abordagens teóricas das Ciências Sociais, defendendo o uso combinado dessas diferentes perspectivas, sejam elas holistas, individualistas ou interacionistas. O importante nesse processo é separar os elementos ideológicos dos componentes metodológicos dessas abordagens, utilizando-os de forma razoável no estudo de questões concretas.

Tentar, no âmbito das configurações de pensamento contemporâneas das ciências sociais, distinguir entre uma postura metodológica (produtiva - em condições empíricas - em termos de conhecimento) e uma dimensão ideológica (contraproducente em termos de conhecimento - mas, não necessariamente em termos políticos ou sociais) não é para nós uma posição filosófica, mas um segredo de nosso ofício, um segredo particularmente importante, principalmente se fazemos da busca do rigor um objetivo central (Olivier de Sardan, 2008a: 249).

Após recusar o uso ideológico das diferentes perspectivas teóricas (holistas, individualistas, interacionistas), Olivier de Sardan (2008a: 256) defende um uso plural (ou eclético) dessas formas de abordagem do social, apesar de estar ciente das dificuldades que essa postura apresenta ("é difícil reivindicar de maneira forte o ecletismo teórico e uma certa prudência é necessária"). 
O uso eclético de contribuições oriundas de diferentes corpos teóricos aparecem para Olivier de Sardan (1995: 91) como uma necessidade de romper com o espírito de escola ${ }^{22}$ e a compreensão de que as disputas de paradigmas nas ciências sociais implica uma espécie de lei, segundo a qual "cada novo ponto de vista se constitui através da oposição ao ponto de vista anterior", contribuindo, dessa forma, para a formação de ortodoxias e não para o diálogo entre diferentes pontos de vista.

Todavia, justamente o uso eclético de abordagens diferentes ${ }^{23}$ quanto ao papel do ator e da estrutura nos estudos sobre desenvolvimento será objeto de uma crítica dirigida a Olivier de Sardan por autores da chamada Escola de Wageningen. Como apresento em seguida, Arce \& Long (2007) defendem a utilização de uma perspectiva centrada nos atores como o caminho mais interessante da análise de processos de desenvolvimento, destacando, por outro lado, os problemas relacionados com a utilização do conceito de entrelaçamento das lógicas sociais.

O uso eclético de dois conceitos - campo e arena - também nos parece um elemento discutível da perspectiva teórica defendida pela socioantropologia do desenvolvimento, uma vez que eles remetem a corpos teóricos (pelo menos o conceito de campo) bastante fechados, motivo pelo qual sustento que a utilização de um e de outro não pode ser feita de forma tão livre como propugna Olivier de Sardan.

\subsection{Interacionismo metodógico ou teoria centrada nos atores?}

Após criticar a disputa entre individualismo e holismo metodológico, procurando situar-se a meio caminho dessas abordagens, Olivier de Sardan defende, em outro momento, uma abordagem classificada como interacionista metodológica, ${ }^{24}$ o que lhe permite apresentar a perspectiva da antropologia do desenvolvimento da APAD e da Escola de Wageningen como centradas na análise do "entrelaçamento das lógicas sociais" dos diferentes atores presentes nas arenas em quem se desenrolam os processos de desenvolvimento (Olivier de Sardan, 2001).

Como sugerem os autores da socioantropologia do desenvolvimento, tomar a ideia do entrelaçamento das lógicas sociais como chave para a análise dos processos de desenvolvimento implica considerar as múltiplas lógicas que funcionam nesses processos, observando como elas se combinam ou se rejeitam, dando origem a um fenômeno novo, que é o resultado da ação desenvolvimentista, produto este diferente do que foi projetado pelos agentes do desenvolvimento ou dos interesses do público-alvo da ação desenvolvimentista.

A noção de entrelaçamento implica uma ideia de mescla, de mistura, de interpenetração de estratégias e lógicas sociais que dão origem a um produto final dotado de qualidades próprias, no qual não é possível reconhecer a marca dos seus componentes iniciais (Bierschenck, 2007: 33). 
Contudo, em artigo apresentado na obra comemorativa dos trabalhos de Olivier de Sardan (Bierschenck et al., 2007), Alberto Arce e Norman Long - representantes da Escola de Wageningen - recusam a ideia de que seus trabalhos possam ser considerados como baseados no entrelaçamento de lógicas sociais, defendendo a perspectiva de análise centrada nos atores.

A maior vantagem da análise centrada no ator é que ela permite explorar um amplo
leque de capacidades que os atores possuem para intervir no mundo material e
social, conferindo especial atenção aos tipos de conflitos e negociações relaciona-
das com as formas de interface social e a emergência de práticas que modificam
modos de vida e identidades existentes e que não podem ser facilmente assimi-
ladas nas rotinas estabelecidas cotidianamente. Tais relações sociais e interfaces
enriquecem as experiências de vida dos atores por meios que afetam suas liga-
ções e sentimentos individuais. Esses últimos não podem ser reduzidos de forma
simples à noção de entrelaçamento de lógicas sociais (Arce \& Long, 2007: 108-109).

Arce \& Long (2007: 109) também criticam a ideia de que sua abordagem possa ser reduzida ou enquadrada em uma análise que tem como elemento central o conceito de lógicas sociais. Para esses autores, pensar o desenvolvimento a partir do cruzamento de diferentes lógicas elaboradas por grupos sociais acaba por conferir um aspecto esquemático e fixo às dimensões mais importantes que caracterizam uma interação, ou seja, os elementos contingentes, ambivalentes e heterogêneos que marcam as ações sociais. Por este motivo eles preferem utilizar a noção de interface, a partir da qual procuram apreender o movimento dos atores nas situações analisadas.

Podemos compreender melhor essa opção desses autores pelo conceito de interface vis-à-vis o de entrelaçamento das lógicas sociais pelo foco do primeiro na interação dos indivíduos em relação - os "elos e redes que se desenvolvem entre indivíduos ou partes" (Long, 2007: 142) -, o que pode permitir aos autores da escola de Wageningen um certo desleixo com os componentes mais estruturais que marcam as situações de desenvolvimento ou a fazer com que eles propugnem a necessidade da reconstrução do conceito de estrutura (Long \& Van Der Ploeg, 1994) em termos que, segundo nossa interpretação, o conceito de estrutura acaba perdendo sua substância, uma vez que ele é pensado como produto da "contínua interação e transformação recíproca dos projetos dos atores” (Long, 2007: 130).

Esse viés interacionista do conceito de estrutura de Long e seus colegas talvez possa ser justificado pelo tipo de objeto de estudo abordado (transmissão de conhecimentos, interação camponeses $x$ técnicos, relação dos camponeses com o mercado), mas é de difícil sustentação quando pensamos em situações de desenvolvimento que envolvem o deslocamento forçado de pessoas para a construção de hidrelétricas (Castro, 1989; Magalhães, 1991), para bases militares (Souza Filho, 2009) ou outros tipos de grandes projetos industriais (Vainer \& Araújo, 1992). 


\subsection{Arena ou Campo?}

Um dos recursos utilizados pela socioantropologia do desenvolvimento para abordar as situações de desenvolvimento é o conceito de arena, ${ }^{25}$ apesar da utilização por parte dos seus autores do conceito de campo ${ }^{26}$ e, por vezes, da citação da expressão configuração (configuração desenvolvimentista).

Para a socioantropologia do desenvolvimento, uma arena ${ }^{27}$ se caracteriza como um lugar de confronto entre grupos (atores) estratégicos heterogêneos movidos por interesses (materiais e simbólicos), atores esses dotados de "poderes relacionais distribuídos de forma desigual" (Olivier de Sardan, 1995: 174). Por outro lado, assinala que arena é também uma noção de natureza interacionista, que toma um espaço social em um sentido mais imediato no qual os atores possuem algum tipo de consciência das disputas que se desenrolam em seu interior.

[o conceito de arena] Evoca, ao mesmo tempo, uma escala mais restrita e uma consciência mais clara dos enfrentamentos por parte dos atores. Uma arena, no sentido que nós a entendemos, é um lugar de confrontações concretas de atores sociais em interação acerca de questões comuns. Ela se refere a um espaço "local". Um projeto de desenvolvimento é uma arena. [...]. Arena possui um conteúdo descritivo mais forte que o de campo (Olivier de Sardan, 1995: 178-179).

Algumas das características citadas nessa definição mostram que, apesar de próximos, os conceitos de arena e de campo não são intercambiáveis, pois, como argumenta Olivier de Sardan, o conceito de campo possui um uso de natureza mais macro e é trabalhado numa perspectiva estrutural, "mesmo se o uso da imagem do jogo e as referências ao habitus introduzem uma dimensão estratégica e permitem levar em consideração as tomadas de posição dos agentes" (Olivier de Sardan: 178, grifo no original).

Contudo, apesar de apontar essas diferenças e sua preferência pelo conceito de arena, Olivier de Sardan (2001: 731) defende a possibilidade da utilização da análise do desenvolvimento em termos da teoria dos campos, com o detalhe que o uso dessa teoria exigiria uma descrição mais pronunciada do sistema de força e das posições estatutárias ocupadas pelos agentes da arena/campo desenvolvimentista em questão. Trabalhando nessa perspectiva, Lavigne-Delville (1999) argumenta que o uso da teoria dos campos seria um complemento indispensável à análise microssociológica do jogo de atores em configurações desenvolvimentistas concretas. Para esse autor:

[...] uma análise bourdieusiana em termos de campo, de sistema de posições e de disposições seria, sem nenhuma dúvida, frutífera para pôr em evidência as lógicas estruturais e os mecanismos de reprodução do sistema de ajuda (do desenvolvimento), sua hegemonia crescente e sua capacidade de neutralizar as análises críticas produzidas com regularidade no interior e fora do sistema de ajuda ao desenvolvimento (Lavigne-Delville, 1999: 22). 
Aqui aparece uma vez mais o "ecletismo impenitente" dos autores da socioantropologia do desenvolvimento, ao proporem o uso de conceitos oriundos de abordagens teóricas opostas para o estudo de situações de desenvolvimento. Entretanto, é possível questionar sobre a pertinência da complementaridade entre uma análise micro (arena) e uma perspectiva macro (campo), uma vez que o estudo de situações sociais em termos da teoria dos campos implica considerar os agentes (com suas disposições e habitus) de uma forma bastante diferente da que normalmente é utilizada numa abordagem que pensa os atores em interação (arena) com uma forte capacidade de agência, de manipulação dos recursos e da própria situação. ${ }^{28}$

A esse respeito podemos citar a crítica de Bourdieu ao interacionismo (metodológico) da abordagem dos fenômenos econômicos em termos de redes sociais, solução que, segundo esse autor, tem por consequência "fazer desaparecer todos os efeitos da estrutura social e todas as relações objetivas de poder", representando uma falsa alternativa ao debate entre holismo e individualismo metodológico (Bourdieu, 2000: 242).

Além dessa crítica, outra dificuldade em conciliar estudos sobre processos de desenvolvimento com a teoria dos campos diz respeito ao tipo de investimento investigativo que essa teoria exige, com a análise do tipo de capital específico do campo em questão, das disposições e do posicionamento dos agentes nesse campo, ${ }^{29}$ das relações estabelecidas com outros campos (campo político, campo intelectual), o que faz com que, na maior parte das vezes, a menção à teoria dos campos realizada por estudiosos do desenvolvimento seja de natureza apenas metafórica. ${ }^{30}$

De forma semelhante, mas em sentido contrário, outros utilizadores do conceito de arena na socioantropologia francesa, como Daniel Céfai (1996), procuram sublinhar as diferenças desse conceito em relação ao de campo, recusando a ideia de que os atores se orientem na arena buscando acumular diferentes espécies de capitais e que a publicidade (que marca o conceito de arena pública) seja uma espécie de illusio que caberia à análise sociológica desconstruir.

Creio que não por outro motivo as posições mais recentes dos defensores da socioantropologia do desenvolvimento (Olivier de Sardan, 2005; 2007) são marcadas pelo privilegiamento de uma abordagem centrada na interação e pela utilização do conceito de arena, ${ }^{31}$ deixando de lado os componentes mais estruturais (ou "dominocêntricos") que normalmente estão associados à abordagem de Bourdieu. ${ }^{32}$ 


\section{CONCLUSÃO}

Um dos principais méritos da socioantropologia do desenvolvimento é o de procurar estabelecer uma base consistente aos estudos sobre os processos de desenvolvimento, conferindo a esse campo de investigação um estatuto teórico respeitável em consonância com o debate contemporâneo das Ciências Sociais.

Nesse movimento, seus defensores foram levados a refinar sua argumentação, detalhando suas escolhas teóricas ao mesmo tempo em que se posicionaram face às abordagens concorrentes, escolhendo o populismo metodológico e a antropologia do desenvolvimento pós-estruturalista como adversários, ${ }^{33}$ ao mesmo tempo em que procuram estabelecer uma aliança com os trabalhos de Norman Long e seus colegas da Universidade de Wageningen. ${ }^{34}$

Se no campo dos estudos sobre desenvolvimento a posição da socioantropologia do desenvolvimento é clara e facilmente sustentável, com sua recusa aos excessos do populismo ideológico e da abordagem desconstrutivista, suas escolhas no debate mais amplo das Ciências Sociais nem sempre se mostraram coerentes, necessitando de retificações a posteriori.

A tentativa de conciliar conceitos oriundos de escolas teóricas diferentes (campo e arena), bem como o esforço em unificar um conjunto de trabalhos sobre o desenvolvimento em torno da ideia do entrelaçamento de lógicas sociais mostram as dificuldades enfrentadas por uma abordagem que, situando-se num campo disciplinar específico (da socioantropologia desenvolvimento), tem de enfrentar o desafio de produzir explicações que lidam com os principais termos do debate contemporâneo das Ciências Sociais.

Afinal de contas, que tema mais espinhoso para enfrentar o debate sobre a articulação entre ação e estrutura, acerca das relações entre dimensões macro e micro da vida social (Olivier de Sardan, 2008a: 246-252) ${ }^{35}$ que o das operações de desenvolvimento? Como pensar, por exemplo, a relação entre comunidades ou grupos sociais atingidos por obras de grande envergadura - vide a literatura sobre a implantação de grandes projetos de investimento (Ribeiro, 1991; Vainer \& Araújo, 1992) - sem entrar no debate sobre dominação e resistência?

A crítica polida de Arce \& Long (2007) à tentativa de resolver parte desse debate com o recurso ao conceito de entrelaçamento das lógicas sociais mostra que o esforço da socioantropologia do desenvolvimento em pôr um fim às querelas entre escolas de pensamento (Olivier de Sardan, 2008a: 256) está longe de ser alcançado, exigindo um esforço maior na apresentação dos seus argumentos interpretativos.

O anúncio da ampliação do campo de estudos dessa abordagem, designada agora como uma socioantropologia dos espaços públicos africanos ${ }^{36}$ (Olivier de Sardan, 2007), apenas amplia os desafios dessa proposta de investigação, que estende seus horizontes para um leque maior de objetos de investigação. 
Marcelo Sampaio Carneiro é doutor em Sociologia pela Universidade Federal do Rio de Janeiro (UFRJ), com estágio na École de Hautes Études en Sciences Sociales (EHESS). É professor do Programa de Pós-Graduação em Ciências Sociais da Universidade Federal do Maranhão (UFMA). Publicou recentemente (em co-autoria) os livros: A terceira margem do rio: ensaios sobre a realidade do Maranhão no novo milênio (2009) e A agricultura familiar da soja na região sul e o monocultivo no Maranhão (2008); e o artigo: "Entre o Estado, a sociedade e o mercado: análise dos dispositivos de governança da indústria florestal na Amazônia” (2012). 


\section{NOTAS}

1 Também identificada como antropologia do desenvolvimento da APAD, rede de pesquisadores que foi criada no início dos anos 1990 e, como o próprio nome sugere, reúne pesquisadores e praticantes europeus e africanos que têm no estudo de processos de desenvolvimento seu objetivo comum (Bierschenck, 2008).

2 Essa reflexão nasceu nas discussões realizadas no âmbito do projeto de pesquisa "Amazônia e os Paradigmas do Desenvolvimento", que foi desenvolvido com recursos do Programa de Cooperação Acadêmica da Coordenação de Aperfeiçoamento de Pessoal de Nível Superior - CAPES (PROCAD) e que contou com a participação de professores do Programa de Pós-Graduação em Ciências Sociais da Universidade Federal do Amazonas (PPGCSOC/UFMA), do Programa de Pós-Graduação em Sociologia e Antropologia da Universidade Federal do Rio de Janeiro (PPGSA/UFRJ) e do Programa de Pós-Graduação em Ciências Sociais da Universidade Federal do Pará (PPGCS/UFPA).

3 A APAD possui um boletim disponível na internet no qual podem ser encontradas contribuições sobre os principais temas estudados por seus pesquisadores. Ver <http://apad. revues.org/>. O manifesto de lançamento da associação está disponível no seu primeiro boletim: <http://apad.revues.org/327>.

4 Olivier de Sardan (2001) critica também a vertente de análise que denomina de populismo ideológico, exemplificada pelo trabalho de M. Hobbart, a partir da distinção que faz entre um populismo de boa qualidade (metodológico), que procura levar em conta as capacidades dos atores, contra um tipo de populismo (ideológico) que entrava a capacidade de conhecimento, ao valorizar de forma acrítica o saber e as competências desses atores.

5 Os estudos sobre desenvolvimento realizados pela denominada escola de Wageningen (Holanda) referem-se aos trabalhos impulsionados, a partir de 1981, por Norman Long e que serão identificados pela etiqueta da "análise orientada para os atores" (Guivant, 1997; De La Pena, 2007).

6 Para Bierschenk (2008: 6-7) o antecedente histórico dessa utilização da antropologia por instituições de desenvolvim- 
entos é a antropologia aplicada, tal como esta foi elaborada por antropólogos americanos desde os anos 1930, em trabalhos sobre reservas indígenas, organizações industriais e estudos de comunidades rurais, no âmbito do New Deal da administração Roosevelt.

7 A evolução do número de antropólogos no âmbito da USAID é destacada por Viola (2000: 26), que passam de 1, em 1974, para 22, em 1977, e 50, em 1980. Escobar (1991: 666) chama a atenção para o fato que essa expansão ocorrerá também em organizações privadas que passam a se apresentar como portadoras da expertise necessária para realizar estudos que incorporam a perspectiva da antropologia associada ao desenvolvimento.

8 A. Hirschman argumenta que o declínio da prática e da teoria do desenvolvimento está referida à sua fragilidade teórica e à "sucessão de desastres políticos que se produziram em numerosos países do terceiro mundo a partir dos anos 60 - desastres ligados evidentemente, de um modo ou de outro, às tensões produzidas pelo desenvolvimento e pela modernização" (Hirschman, 1985: 74).

9 O termo pós-desenvolvimento recobre um conjunto de iniciativas que vêm sendo desenvolvidas de forma autônoma por grupos sociais em diversas partes do mundo. Segundo a interpretação proposta por Rist (2007), a principal característica dessas iniciativas é sua autonomia face ao mercado e ao Estado.

10 Como destaca Bierschenck, a fragilidade desse tipo de abordagem tem como marco o fato de que "o discurso é confundido com a prática e os efeitos anunciados com a realidade" e pelo tratamento da "máquina desenvolvimentista como uma caixa-preta, pois não sabemos como e por quem o discurso (do desenvolvimento) é produzido e, ainda menos, como ele é recebido e pode ser desconstruído" (Bierschenck, 2008: 13).

11 Como no caso dos conceitos de populismo, individualismo e holismo, Olivier de Sardan também distingue um bom e um mau uso do conceito de interação. O mau uso do conceito de interação seria aquele que o confina às "situações de interação e na busca de uma gramática formal dessas interações (os trabalhos de orientação etnometodológica ilustram bem essas armadilhas)" (Olivier de Sardan, 2001: 742). 
12 Esse é também o espírito da sociologia do desenvolvimento orientada para os atores de Norman Long e seus colaboradores (Long \& Van Der Ploeg, 1994; Long, 2007).

13 O polo oposto dessa abordagem seria o que Olivier de Sardan (1995: 106-107) classifica como "miserabilismo", que consistiria em negar qualquer capacidade aos despossuídos de reagirem face aos mecanismos de dominação, tomando como referência a crítica de Jean-Claude Passeron a algumas análises de Pierre Bourdieu.

14 Para Bierschenck (2008: 4) as diferenças entre esses dois tipos de antropologia do desenvolvimento podem também ser relacionados a algumas características específicas dos locais (Europa e América do Norte) de sua elaboração. Diferenças que dizem respeito ao pertencimento a comunidades epistêmicas, a tradições discursivas, bem como ao mercado editorial.

15 Dentre os temas novos indicados para a investigação estão o estudo dos "antecedentes históricos do desenvolvimento; a etnografia das instituições do desenvolvimento, das linguagens e suas subdivisões; a análise da contestação e das resistências as intervenções do desenvolvimento; as biografias críticas e as autobiografias dos praticantes do desenvolvimento" (Escobar, 1997: 548).

16 Segundo Céfai (2003: 471) essa separação foi erodida, entre outras coisas, pela utilização crescente da etnografia para o estudo de questões que eram exploradas unicamente por sociólogos, "abrindo caminho para uma autorreflexão sobre as figuras da modernidade"

17 O que equivale à defesa de um papel reformista para a socioantropologia do desenvolvimento: "O papel prático das Ciências Sociais não deve se reduzir unicamente a uma função crítica e de protesto. A modéstia do reformismo, em matéria do desenvolvimento como alhures, possui tanta grandeza quanto a bravura do denuncismo" (Olivier de Sardan, 2004: 38).

18 Como destaca Baré (1997: p.142): “entre decisões ou orientações macroeconômicas e a instalação de políticas e projetos de ajuda existe todo um conjunto de mediações institucionais e humanas que possuem relação com as consequências dessas ações". A crítica da suposta racionalidade 
da ação planejada pelo Estado também é um dos focos das análises de Long (1982, 2007).

19 Experiências que foram apoiadas no âmbito do PDA, subprograma integrante do PPG-7, que visava identificar e apoiar formas sustentáveis de gestão dos recursos naturais na Amazônia e na Mata Atlântica. Uma avaliação dessas experiências desenvolvidas na Amazônia pode ser verificada no trabalho "Estudos da Amazônia: avaliação de vinte projetos PDA" (Brasil, 2004).

20 Em obra recente, Olivier de Sardan (2008a: 9) discute os aspectos epistemológicos da produção de conhecimento pela socioantropologia, chamando a atenção para a crítica da ilusão realista oriunda do positivismo clássico, ao mesmo tempo em que defende a existência de um real de referência, passível de ser conhecido (de forma parcial) através dos instrumentos de investigação.

21 Guivant (1997: 422) faz uma crítica pertinente desse tipo de idealização existente nos discursos que defendem a agroecologia, contrapondo-a de forma dicotômica ao conhecimento científico-técnico.

22 Exceção feita à crítica constante desse autor às abordagens culturalistas que marcam parte importante dos estudos antropológicos. Para Olivier de Sardan, o culturalismo funciona como uma espécie de holismo ideológico na antropologia, reduzindo as realidades estudadas ao conceito de cultura, pensado como algo homogêneo e que explica o funcionamento dessa realidade (Olivier de Sardan, 2008a: 33; 2008b: 10).

23 Outro tipo de crítica é a feita por Copans (2007: 7), que contesta a socioantropologia do desenvolvimento - um tipo nobre de antropologia sem nome, técnica, sem referência e história - por inibir o estabelecimento de uma verdadeira antropologia social na África.

24 Vale destacar que a etiqueta do interacionismo metodógico é cunhada também para designar a perspectiva teórica representada por Simmel, conforme interpretação proposta por Vandenberghe (2005: 95).

25 O conceito de arena é apresentado conjuntamente com o de grupo estratégico e o de conflito, compondo o arsenal de instrumentos de investigação a serem mobilizados pela 
socioantropologia do desenvolvimento (Olivier de Sardan, 1995: 176).

26 O conceito de campo nos permite analisar as situações de desenvolvimento como um todo estruturado no qual determinados agentes (dominantes/dominados), dotados de um conjunto variado (em termos de volume e estrutura) de capitais, estabelecem relações de cooperação e disputa (Bourdieu \& Wacquant, 1992).

27 Definida como arena política, uma vez que as ações analisadas ocorrem sempre em um contexto de "confrontação e de luta de influência entre um conjunto de atores sociais que estão implicados [...] com a busca de vantagens e de inconvenientes que toda ação de desenvolvimento supõe" (Olivier de Sardan, 1995: 175).

28 Norman Long trabalha com o conceito de campo social, contudo, faz questão de destacar a diferença entre sua abordagem - que inclui os conceitos de arena e domínio da perspectiva estrutural que o conceito de campo assume com Bourdieu (Long, 2007: 123).

29 Como assinalou Loïc Wacquant (Bourdieu \& Wacquant, 1992: 24) os conceitos de campo e habitus são inseparáveis. O habitus significando os esquemas mentais e corporais de percepção, apreciação e ação que possibilitam a atuação dos agentes no campo, e este último fornecendo o quadro geral em que essa ação transcorre.

30 Esse é o caso, por exemplo, da utilização desse conceito por Ribeiro (2008) em artigo sobre o campo do poder presente nas ações de desenvolvimento.

31 Outro tipo de crítica feita ao uso do conceito de arena por Olivier de Sardan remete à dificuldade em isolar nos estudos sobre situações de desenvolvimento as influências de atores que não estão diretamente envolvidos, em contato, no espaço local estudado, mas que desempenham um papel fundamental na elaboração da ajuda ao desenvolvimento (Baré, 2007: 608).

32 Para uma crítica à utilização indiscriminada da teoria dos campos, ver Lahire (2001), que sublinha, entre outros aspectos, que nem todas as esferas da vida social são passíveis de uma análise em termos dessa teoria. 
33 Em texto produzido em 2008, com reflexões elaboradas a partir de cursos realizado na New School for Social Research de Nova York, Bierschenck relativiza um pouco essa oposição entre a socioantropologia do desenvolvimento e a nova antropologia do desenvolvimento anglófona, destacando as características próprias de cada um desses estilos de fazer antropologia do desenvolvimento, conforme indicado na nota 14 .

34 Além dos pontos em comum ressaltados ao longo do artigo entre essas duas abordagens, vale sublinhar que a abordagem centrada nos atores também critica a forma como os autores pós-estruturalistas utilizam o conceito de discurso (Long, 2007: 315).

35 Para Chauveau (2007), a combinação da descrição em senso restrito, fundada na observação de campo, com a descrição em sentido amplo, baseada em dados não observados, proposta por Olivier de Sardan permanece um tema não resolvido pela socioantropologia do desenvolvimento.

36 Como destaca Olivier de Sardan (2007: 548): “Os temas da socioantropologia dos espaços públicos africanos, que se referem no seu essencial ao estudo da produção e gestão de bens e serviços públicos ou coletivos na África, incluem, por conseguinte, as operações de desenvolvimento". 


\section{REFERÊNCIAS BIBLIOGRÁFICAS}

Baré, Jean-François. De l'anthropologie au developpement et retour. Revue Tiers Monde, 2007, 191, p. 591-610.

. L'anthropologie et les politiques de développement. Terrain, 1997, 28. Disponível em <http://terrain.revues.org/ document3180.html $>$. Acesso em 1 out. 2008.

Bierschenck, Thomas. Anthropologie et développement. Historiciser et localiser les approches. Working Papers, 2008, 87b. Department of Anthropologiy and African Studies, Universitat Johannes Gutemberg - Mainz.

. Enchevêtrement des logiques sociales : Jean-Pierre Olivier de Sardan, un anthropologue du développement. In: Bierschenck, Thomas et alli (orgs.). Une anthropologie entre rigueur et engagement. Paris/Leiden: Karthala/APAD, 2007, p. 25-47.

et al. (orgs.). Une anthropologie entre rigueur et engagement: Essais autour de l'oeuvre de Jean-Pierre Olivier de Sardan. Paris/Leiden: Karthala/APAD, 2007.

Boltanski, Luc. L'amour et la justice comme compétences: trois essais de sociologie de l'action. Paris: Ed. Métailié, 1990.

Boudon, Raymond. Grandeur et décadence des sciences du développement: une étude de sociologie de la coinassance. L'Année Sociologique, 1992, 42, p. 253-274.

Bourdieu, Pierre. Les structures sociales de l'économie. Paris: Seuil, 2000.

\& Wacquant, Loïc. Réponses - Por une anthropologie réflexive. Paris: Seuil, 1992.

Brasil. Ministério do Meio Ambiente. Secretaria de Coordenação da Amazônia. Programa Piloto para Proteção das Florestas Tropicais. Subprograma Projetos Demonstrativos. Estudos da Amazônia: Avaliação de vinte projetos PDA. Brasília: Ministério do Meio Ambiente, 2004.

Carneiro, Marcelo S. Investimento estatal e movimentos sociais na Amazônia Oriental: breve análise do início da década. Desenvolvimento \& Cidadania, 1994, 3/13, p. 21-27. Entre o Estado, a sociedade e o mercado: análise dos dispositivos de governança da indústria florestal na Amazônia. Cadernos do CRH, 2012, 25, p.73-86. 
Castro, Edna M. R. Resistência dos atingidos pela barragem de Tucuruí e construção de identidades. In: Castro, Edna \& Hébete, Jean (orgs.). Na trilha dos grandes projetos. Cadernos do Naea, 1989, 10. Belém: NAEA/UFPA.

Céfai, Daniel. Postface - L'enquête de terrain en sciences sociales. In: __-_ (org.). L'enquête de Terrain. Paris: La Découverte/MAUSS, 2003, p. 467-615.

. La construction des problèmes publics. Définitions de situations dans des arènes publiques. Réseaux, 1996, 14/75, p. 43-66.

Cernea, Michel M. El conocimiento de las ciencias sociales y las politicas y los projectos de desarrollo. In: __-_ (org.). Primero la gente. Variables sociológicas en el desarrollo rural. México, D. F.: Fondo de Cultura Económica, 1995, p. 25-66. Chaveau, Jean-Pierre. Socio-anthropologie et variation d'echelle. Ouvrir le jeu entre "rigueur du qualitative" et "interpretation au sens large". In: Bierschenck, Thomas et alli (orgs.). Une anthropologie entre rigueur et engagement: Essais autour de l'oeuvre de Jean-Pierre Olivier de Sardan. Paris/ Leiden: Karthala/APAD, 2007, p. 443-474.

Copans, Jean. Les frontières africaines de l'anthropologie. Un demi-siècle d'interpellations. Jounal des Anthropologues, 2007, 110-111. Disponível em <http://jda.revues.org/2499. html>. Acesso em 5 mar. 2011.

De La Pena, Guillermo. Presentación. In: Long, Norman. Sociología del desarrollo: una perspectiva centrada en el actor. México, D. F.: Centro de Investigaciones y Estudios Superiores en Antropología Social, 2007, p. 7-11.

Dosse, François. L'empire du sens. L'humanisation des sciences humaines. Paris: La Découverte, 1995.

Escobar, Arturo. Anthropology and and development encounter: the making and marketing of development anthropology. American Ethnologist, 1991, 18/4, p. 658-682.

. El desarrollo sostenible. Dialogo de discursos. Ecologia Política, 1995, 9, p. 7-26.

La invención del Tercer Mundo - construcción y deconstrucción del desarrollo. Barcelona: Grupo Editorial Norma, 1996. . Anthropologie et développement. Revue Internationale des Sciences Sociales, 1997, 154, p. 539-559. 
Faugère, Elsa. Regards sur la culture développementiste: representations et effets non intentionnels. Document de Travail, $\mathrm{n}^{\circ}$ 20. Paris: GRET, 2000.

Guivant, Julia S. Heterogeneidade de conhecimentos no desenvolvimento rural sustentável. Cadernos de Ciência e Tecnologia, 1997, 14/3, p. 411-446.

Hamel, Jacques. La socio-anthropologie, un nouveau lien entre la sociologie et l'anthropologie. Socio-anthropologie, 1997, 1. Disponível em <http://socio-anthropologie.revues. org/index73.html>. Acesso em 5 mar. 2011.

Hart, Keith. Quelques confidences sur l'anthropologie du développement. Ethnographiques, 2002, 2. Disponível em <http://ethnographiques.org/documents/article/arHart. html>. Acesso em 20 ago. 2005.

Hirschman, Albert. A economia como ciência moral e política. São Paulo: Brasiliense, 1985.

Juan, Salvador. La "socio-anthropologie": champ, paradigme ou discipline? Regards particuliers sur les entretiens de longue durée ou d'observation. Bulletin de Méthodologie Sociologique, 2005, 87. Disponível em <http://bms.revues. org/index869.html>. Acesso em 26 mar. 2011.

Lahire, Bernard. Champ, hors-champ, contrechamp. In:

(org.). Le travail sociologique de Pierre Bourdieu: dettes et critiques. Paris: La Découverte, 2001, p. 23-57.

Lavigne-Delville, Philippe. Impasses cognitives et expertise en sciences sociales: refléxions à propos du développement rural en Afrique. Coopérer Aujourd'hui, 1999, 9 (GRET, Les documents de la Direction scientifique, 28p.)

Lima, Eirivelthon et al. Florestas familiares: um pacto sócioambiental entre a indústria madeireira e a agricultura familiar na Amazônia. Belém: IPAM, 2003.

Long, Norman. Sociologia del desarrollo: uma perspectiva centrada em el actor. México, D. F: Centro de Investigaciones y Estudios Superiores en Antropología Social, 2007.

. Du paradigme perdu au paradigme.... retrouvé? Por une sociologie du développement orientée vers les acteurs. Le Bulletin de l'APAD, 1994, 7. Disponível em <http://apad. revues.org/document2183.html>. Acesso em 15 ago. 2009. . Introdução à sociologia do desenvolvimento rural. Rio de Janeiro: Zahar, 1982. 
\& Van Der Ploeg, Jan. Heterogeneity, actor and structure: towards a reconstitution of the concept of structure. In: Booth, D. (org.). Rethinking social development: Theory, research and practice. Londres: Longmans, 1994, p.62-89.

Lebrecque, Marie France. L'anthropologie du développement au temps de la mondialisation. Anthropologies et Sociétés, 2000, 1/24, p. 57-78.

Magalhães, Sonia. Expropriação e mobilização - a dupla face da relação entre os grandes projetos e a população camponesa. In: Hébette, Jean (org.). O cerco está se fechando: o impacto do grande capital na Amazônia. Petrópolis/Rio de Janeiro/Belém: Vozes/FASE/NAEA, 1991, p. 176-198.

Olivier de Sardan, Jean-Pierre. La rigueur du qualitatif. Les contraentes empiriques de l'interpretation sócio-anthropologique. Louvain-la-Neuve: Bruylant-Academia, 2008a.

. A la recherche des normes pratiques de de la gouvernance réelle en Afrique. Discussion Paper, $n^{\circ}$ 5, Londres: DFID, 2008b.

. De la nouvelle anthropologie du développement à la socio-anthropologie des espaces publics africains. Revue Tiers Monde, 2007, 191, p. 543-552.

. Classic ethnology and the socio-anthropology of public spaces. New themes and old methods in European African Studies. Afrika Spectrum, 2005, 40, p. 485-497.

. Le chainôn manquant. Courrier de la Planète, 2004, 74, p. 36-40.

. Les trois approches en anthropologie du développement. Reuue Tiers Monde, 2001, 168, p. 729-754.

. Anthropologie et developpment: essai en socio-anthropologie du changement social. Paris: APAD/Karthala, 1995.

Pinto, Lúcio F. Carajás. O ataque ao coração da Amazônia. Rio de Janeiro: Marco Zero, 1982.

Ranc, Elisabeth. L'anthropologie du developpement aux États-Unis: forces et promesses d'une nouvelle profession. Cahiers des Sciences Humaines, 1988, 24/4, p. 453-469.

Recasens, Andreu V. Antropología, desarrollo y post-estructuralismo. Entrevista com Arturo Escobar. Quaderni de l'Institu Catalá d'Antropologia, 2000, 13-14, p. 145-160. 
Rist, Gilberto. Le développement. Histoire d'une croyance occidentale. 3. ed. Paris: Les Presses de Sciences Po, 2007.

Ribeiro, Gustavo L. Poder, redes e ideologia no campo do desenvolvimento. Novos Estudos CEBRAP, 2008, 80. Disponível em <http://www.scielo.br/scielo.php?script=sci arttext\&pid=S0101-33002008000100008\&lng=pt\&nrm=iso $>$. Acesso em 3 jan. 2011.

Empresas Transnacionais. Um grande projeto por dentro. São Paulo/Rio de Janeiro: Anpocs/Marco Zero, 1991.

Souza Filho, Benedito. Identidade e territorio: a 'guerra' como instrumento de expropriação. In: Ferretti, Sérgio F. \& Ramalho, José Ricardo (orgs.). Amazônia: desenvolvimento, meio ambiente e diversidade sociocultural. São Luis: Edufma, 2009, p. 119-136.

Vainer, Carlos B. \& Araújo, Frederico G. B. Grandes projetos hidrelétricos e desenvolvimento regional. Rio de Janeiro: CEDI, 1992.

Vandeberghe, Frédéric. As sociologias de Simmel. Bauru/Belém: EDUSC/Ed. UFPA, 2005.

Viola, Andreu. La crisis del desarrolismo y el surgimento de la antropología del desarrolho. In: ___ (org.). Antropología del desarrollo. Teorías y estúdios etnográficos en América Latina. Barcelona: Paidós, 2000, p. 9-64. 
Resumo:

Esse artigo tem como objetivo a análise das contribuições de uma abordagem intelectual, denominada socioantropologia do desenvolvimento, para a análise de situações (Programas, projetos, ações) de desenvolvimento. O texto articula dois níveis de reflexão. Inicialmente, a ênfase se dará sobre a trajetória recente dos estudos sobre processos de desenvolvimento, que, partindo de uma crítica à antropologia para o desenvolvimento enunciam o surgimento de novas abordagens. Em um segundo momento, o foco será direcionado para a discussão da socioantropologia do desenvolvimento, destacando a metodologia dessa proposta de investigação, analisando seus pontos fortes e frágeis. Apesar das fragilidades identificadas consideramos que o balanço da proposta da socioantropologia do desenvolvimento é amplamente favorável, principalmente o que concerne ao propósito dessa corrente em estabelecer uma base consistente aos estudos sobre os processos de desenvolvimento, conferindo a esse campo de investigação um estatuto teórico respeitável, em consonância com as questões presentes no debate contemporâneo das Ciências Sociais.

\footnotetext{
Abstract:

This paper aims to analyze the contribution of the approach of the socioanthropology of development to the investigation of development situations, such as programs, projects, and actions. It combines two levels of consideration. The first level emphasizes the recent path of studies on developmental processes, from which new approaches emerge. The second level considers the discussion of the socioanthropology of development, highlighting its methodology and taking stock of its strong and weak points. Despite some fragilities, the approach of the socioanthropology of development is seen as broadly favourable, mainly concerning its goal of providing a solid basis for the studies on the developmental processes, which can bestow on this research field a respectable theoretical status.
}

Palavras-chave:

Socioantropologia; Desenvolvimento; Arenas, Práticas; Discursos.

\section{Keywords:}

Socioanthropology; Development; Arenas; Practices; Discourses. 